\title{
Aureobasidium pullulans
}

National Cancer Institute

\section{Source}

National Cancer Institute. Aureobasidium pullulans. NCI Thesaurus. Code C127690.

A species of yeast-like saprophytic fungi in the phylum Ascomycota with slimy masses of conidia and chains of one to two-celled, thick-walled, darkly pigmented arthroconidia. 